БЛОХИН Константин Владимирович - кандидат исторических наук, ведущий научный сотрудник Центра исследования проблем безопасности РАН (117335, Россия, г. Москва, ул. Гарибальди, 21б; constantinos1@rambler.ru)

СИНИЦЫН Игорь Михайлович - ученый секретарь Центра исследования проблем безопасности РАН(117335, Россия, г. Москва, ул. Гарибальди, 21б; IM_9380752@таil.ru)

\title{
«СТРАТЕГИЧЕСКИЙ ТЕРРОРИЗМ» США КАК УГРОЗА НАЦИОНАЛЬНОЙ БЕЗОПАСНОСТИ РОССИИ: ГЕНЕЗИС И ОСОБЕННОСТИ
}

Аннотация. Предложенная статья посвящена изучению феномена «стратегического терроризма» как элемента глобальной стратегии США по удержанию мирового господства и лидерства, созданию внешних угроз национальной безопасности России. В статье рассматриваются вопросы генезиса этого явления, его природы, Связи с прокси-войной.

Ключевые слова: ЦРУ, джихадизм, внешняя политика США, безопасность России, Аль-Каида, стратегический терроризм, Ближний Восток, геополитика, религиозный фактор терроризма, прокси-война

И нструментальный характер терроризма и его связь с политикой - это альфа и омега политической теории, и ни у одного вдумчивого эксперта, особенно в антитеррористической сфере деятельности, это не вызывает сомнений. Тем не менее как в СМИ, так и на ответственных политических трибунах тиражируется тезис о борьбе США с международным (мировым) терроризмом. Сомнения же в искренности намерений США в этом экзистенциальном противоборстве, с какой бы стороны они ни раздавались, рассматриваются и клеймятся как циничные и несправедливые. Между тем никто не может игнорировать тот факт, что политические цели (особенно США), не декларируемые официально, зачастую прикрываются, маскируются другими, «благородными», такими как защита демократии, борьба с «диктаторскими» режимами и пр. Этот прием характерен для политической культуры США и позволяет умело скрывать истинные стратегические интересы США в мире.

Так, например, геополитическое противоборство с СССР ранее мотивировалось необходимостью «защиты свободы и свободного мира». Но даже когда СССР перестал существовать, экспансионизм США в отношении теперь уже России приобрел иную идеологическую оболочку - сегодня это «борьба с авторитаризмом», агрессивными государствами, а также международным терроризмом (далее - терроризмом). Природу происхождения терроризма невозможно понять вне «большой стратегии» Вашингтона, в которой терроризм выполняет ряд функций. Поощряемый Вашингтоном терроризм позволяет одновременно скрывать мотивы внешней политики США, маскировать их и одновременно выступать средством достижения геополитических целей.

«Стратегические установки некоторых иностранных спецслужб и зарубежных (международных) террористических организаций» являются факторами распространения терроризма [Алексеев 2012: 139].

Цель настоящей статьи состоит в том, чтобы попытаться типологизировать современный терроризм, его роль в решении геостратегических задач США. Важно объяснить как природу появления терроризма, так и формы его проявления. В этой связи обратимся к самому концепту «терроризм», проанализируем факты его проявлений.

В современной американской политологии, а вслед за ней - и в нашей 
начал активно эксплуатироваться термин, обозначающий новое качественное направление международной политики, так называемый стратегический терроризм. По мнению одного из исследователей этого явления Л.В. Савина, «если терроризм понимать как военную стратегию, то он автоматически становится инструментом для достижения политических целей не только со стороны радикальных группировок, но и для государственных акторов» [Савин 2016: 165]. С этой точки зрения представляется целесообразным отметить, что специфика современного геополитического противостояния в мире, прежде всего современных сверхдержав, состоит в том, что оно проявляется не непосредственно, не напрямую, как в годы «холодной войны», а опосредованно - через действия (события) второго плана. В этой связи инструменты такого противостояния (геополитического противоборства) видоизменились. Так, если говорить о США, анализ их деятельности может свидетельствовать о стремлении достичь своих целей, скрывая истинные мотивы и цели своей политики, выдвигая на первый план несуществующую (или искусственно создаваемую) угрозу, заявленная борьба с которой может привести к решению латентных целей. Например, в качестве таковой часто выдвигается стремление США способствовать «продвижению демократии», бороться против государств, «обремененных» диктаторскими режимами, к которым могут быть отнесены любые государства по их усмотрению исходя из собственных критериев. В этой связи все чаще среди экспертного сообщества звучит мнение, что создание террористического государства, такого как ДАИШ (иное название - ИГИЛ ${ }^{1}$ ), является, по всей видимости, исторической новацией геополитического противостояния, a декларируемая борьба с мировым терроризмом - эффективным инструментом удержания желаемого миропорядка через оказание «помощи» государствам, на территории которых действуют террористы. Такая политика помощи оправдывает нахождение на территории таких государств американских «военных советников», и не только, даже без юридически оформленных договоренностей или решения международных компетентных органов. Естественно, подчиненность обозначенного направления деятельности (терроризма) при реализации «большой стратегии» определяет его своеобразие и особенности. «Стратегический терроризм» - термин, который определяет его инструментальную природу (во многом схожую с принципами и целями терроризма), его подчиненность, механизм решения геополитических целей.

По мнению упомянутого автора, а также специалистов- международников, с учетом современных взглядов на причины и сущность терроризма можно выделить, по меньшей мере, три аспекта оценки терроризма в контексте рассматриваемой проблемы. Первый состоит в насильственном характере большинства террористических актов, благодаря чему целевая программа террора отличается от форм ненасильственной пропаганды. Второй аспект состоит в природе самого террористического акта. Ссылаясь на мнение Т. Торнтона, высказанное в статье «Терроризм как оружие политической агитации» [Thornton 1964], можно заключить, что даже политическое насилие может быть признано терроризмом, если оно выходит за рамки норм насильственной политической агитации, принятой в данном обществе. Наконец, третьим аспектом терроризма следует считать символический характер насилия. Теракт будет иметь более широкое значение, чем непосредственные последствия самого акта. «По этой причине террористический акт может быть понятен только при оценке его символического содержания, или “послания” " [Савин 2016: 166-167].

Анализ стратегических документов США позволяет сделать вывод, что в

1 Его деятельность в России запрещена. 
основу реализуемой ими террористической кампании положена так называемая концепция дезориентации, направленная на отчуждение власти от народа и распространение хаоса. В этой связи можно говорить о том, что в историческом контексте США не сразу приступили к реализации этой концепции, решая прежде всего задачу формирования идеологической и материальной основ терроризма, а также создания его кадрового резерва.

Использование террористических методов деятельности США активно стали применять еще в борьбе с СССР. По мнению многих исследователей, «террористическим детищем» ЦРУ стала Аль-Каида во главе с Бен Ладеном. Как отмечают западные источники, «Бен Ладен входил в подпольную сеть ЦРУ, имея задачу вербовать и обучать иностранных боевиков, стекавшихся в Афганистан для борьбы с “неверными” Советами» [Стоун, Кузник 2014: 644].

Знакомство ЦРУ с Бен Ладеном произошло в 1980-х гг. в Судане, который был своеобразной «расчетной палатой для террористов» [Вейнер 2013: 473].

Именно Афганистан стал основательной и прочной платформой для террористической деятельности опекаемых США сил. Позже, в начале нулевых годов, по мнению исследователей, США активно использовали созданную ими самими террористическую инфраструктуру для обеспечения своих геополитических интересов, строительства там сети баз. «В декабре 2004 года в ходе визита в Кабул министр обороны США Дональд Рамсфелд сообщил о планах строительства девяти новых баз в Афганистане в провинции Гильменд, Герат, Нимроз, Балх, Хост и Пактия. Они должны были дополнить три основные американские военные базы, развернутые зимой 2001-2002 годов в начале оккупации Афганистана якобы для купирования и устранения террористической угрозы, исходящей от Усамы бин Ладена» [Вейнер 2013: 298].

Активное наращивание присутствия в регионе американских, британских, а затем и германских сил вело к эскалации военных действий, многочисленным жертвам и появлению ответного джихада. «Ответные действия джихадистов против сил НАТО в регионе служили оправданием для создания здесь новых американских военных баз» [Энгдаль 2016: 299].

Под предлогом войны с терроризмом спецподразделения США активно провоцировали мусульманское население на джихад как ответную меру на вмешательство США. «Наиболее открытое вмешательство после вторжения в Афганистан США совершили на юге Филиппин, выступив против местных повстанцев мусульман из группировки Абу Сайяфа из Фронта исламского освобождения Mopo (MILF). Американцы заявили, что небольшая группа Абу Сайяфа была связана с Бен Ладеном, игнорируя тот факт, что эти радикалы были выходцами из сепаратистского движения Моро, в течение последних 40 лет действовавшего на острове Минданао и архипелаге Сулу» [Энгдаль 2016: 308].

Самой важной точкой отсчета в истории современного терроризма стали трагические события 11 сентября 2001 г., когда Соединенные Штаты Америки были выбраны объектом террористической атаки. Катастрофа 11 сентября стала импульсом для широкомасштабного американского вторжения в Афганистан и Ирак в 2001 и 2003 гг. Борьба США с терроризмом привела и к изменению всего геополитического ландшафта Ближнего Востока, заложив основу для еще более опасного явления - Исламского государства.

Эти террористические атаки на США стали для мировой общественности обоснованием необходимости присутствия США на Ближнем Востоке, а американской элите развязали руки для более активных действий. Так, созданный еще в 1997 г. проект «Новый американский век» (Project for the New American Century - PNAC), в аналитический центр которого вошли будущие члены администрации Дж. Буша-младшего, стал развивать концепцию «стран-изгоев», 
куда входили Иран, Ирак, Сирия и Северная Корея. Впоследствии эти страны были приравнены к «террористическим», и США до сих пор придерживаются курса на смену их режимов.

«Красной линией» для $P N A C$ стала идея сохранения американского лидерства и гегемонии США. Влиятельные неоконсерваторы Гэри Шмит и Дональд Каган еще до событий 11 сентября 2001 г. в докладе «Перестройка американской обороны: стратегия, сила и ресурсы нового столетия» писали, что процесс трансформации мира под американские нужды, даже если он будет сопровождаться революционными изменениями, может затянуться, и лишь катастрофа, сравнимая по масштабам с Перл-Харбором, может стать катализатором перемен 1 .

В начале 1990-х гг. с установлением однополярного мира и с исчезновением главного противника - СССР встал вопрос о выборе новой цели. Таковой стал «исламофашизм» (термин неоконсерватора Нормана Подгореца) и вытекавшая из него идея переформатирования Большого Ближнего Востока, предполагавшие зачистку от неугодных арабских режимов, угрожавших существованию Израиля. Отметим, что эта идея «переформатирования» была заявлена еще до подрыва в Нью-Йорке башен-близнецов и вторжения США в Ирак.

П. Бьюкенен приводит интересный факт: Н. Подгорец, влиятельный издатель неоконсервативного журнала Commentary, советовал Дж. Бушу-младшему развязать «четвертую мировую войну» с «исламофашизмом». Он советовал американскому президенту: «Режимы, которые давно заслуживают свержения... ни в коей мере не ограничиваются тремя отдельными представителями "оси зла" (Иран, Ирак, Северная Корея). Как минимум в это число следует включить Сирию, Ливан и Ливию, а также таких “друзей” Америки, как Саудовская Аравия, Египет, Хосни Мубарака и Организацию освобождения Палестины» [Бьюкенен 2006: 80].

Результатом такой установки влиятельного «мозгового центра», оказывавшего прямое влияние на американское правительство, стала «демократизация» Ближнего Востока, приведшая к хаотизации, разрушению сложившихся государственных структур и светских режимов. «Прежде всего, мы должны свергнуть террористические режимы, начав с “Большой Тройки" - Ирана, Ирака, Сирии. После этого мы можем заняться саудовцами» [Савин 2016: 78].

Важно отметить, что вопрос о стабилизации режимов в регионе вообще не стоял. Это лишний раз доказывает инструментальную природу терроризма. «Мы не хотим стабильности в Иране, Ираке, Сирии, Ливане и даже Саудовской Аравии; мы хотим, чтобы положение дел в этих странах изменилось. Вопрос дня состоит не в том, стоит ли дестабилизировать, а в том, как это сделать» [Бьюкенен 2006: 78]. Дестабилизация режимов происходила за счет подрыва существующих режимов. Легитимными целями становятся представители государства - политики, чиновники, военные, судьи, полиция и т.п., которых представляют как агентов репрессивного режима [Савин 2016: 167].

США не только осуществляли программу «демократизации» Ближнего Востока, но и финансировали джихадистов. Директор ЦРУ генерал Д. Петреус при администрации Б. Обамы фактически курировал деятельность транснациональных компаний «Лафарж и Холсим», которые строили подземные бункеры для террористов в Сирии. Джихадистов поддерживали не только американские мультинациональные корпорации, но и «Тойота», которая поставила тысячи «хайлюксов», вооружение которых было идентичным вооружению спецназа США [Тьерри 2017: 298].

Джихадисты были нацелены не только на войну с сирийским правительством,

${ }^{1}$ Rebuilding America's Defenses: Strategy, Forces and Recourses for a New Century. September 2000. P. 51. 
но и на решение геополитических задач по перекрытию доступа к Шелковому пути. Поэтому террористы получали не только финансовые средства, но и разведывательную информацию с самолетов типа АВАКС в реальном времени [Тьерри 2017: 299]. Когда российские ВКС начали операцию в Сирии, то мэтр американской дипломатии и геополитики 3. Бжезинский прямолинейно заявил, что «Россия уничтожает американские активы в регионе» ${ }^{1}$. Наряду с прямой поддержкой терроризма со стороны США следует отметить и косвенные последствия такой поддержки в форме пополнения и восстановления сил террористов. Так, в докладе правительства США от 2006 г., в котором содержалась оценка обстановки национальной разведкой США (National Intelligence Estimate - NIE), утверждалось, что война в Ираке стимулировала пополнение рядов радикальных мусульманских экстремистов и способствовала формированию новой генерации потенциальных террористов по всему миру. В докладе отмечалось, что число террористов «может расти быстрее», чем действия США и их союзников по ликвидации этих угроз. По общей оценке всех американских разведывательных служб, вторжение США в Ирак и последующий подъем сил сопротивления оккупантам стал «главным источником вдохновения для новых сетей и групп исламских экстремистов, которых объединяло нечто большее, чем просто идея противостояния Западу. Ситуация в Ираке не принесла ожидаемой победы в глобальной борьбе с терроризмом, а лишь еще больше осложнила положение США» [Энгдаль 2016: 308].

Программа по «демократизации» Большого Ближнего Востока была реализована неоконсервативной командой Дж. Буша-младшего в координации с $G-8$ (саммит на Си-Айленде). В 2004 г. Тони Блэр предложил США план свержения светских арабских правительств и их замены «Братьями-мусульманами». Запад отказался от противопоставления «религиозный - светский», которое подтачивало мусульманский мир, и взял в расчет только противопоставление «умеренных националистов», согласившихся сотрудничать с империализмом, «экстремистам», от такого сотрудничества отказавшимся [Тьерри 2017: 201].

С 2006 г. США стали считать «умеренными» джихадистов в Сирии [Тьерри 2017: 202]. Известно, что в США при Совете национальной безопасности был создана засекреченная группа во главе с Лиз Чейни для управления «демократизацией» Ирака и Сирии [Тьерри 2017: 203].

Вопрос о «Братьях-мусульманах» рассмотрим отдельно. По мнению американского исследователя проблемы терроризма У. Энгдаля, «в корне неразумной была стратегия ЦРУ, предполагавшая использование “Братьев-мусульман” и других исламистов в борьбе против христиан, а фанатичных джихадистов против других мусульман: суннитов против шиитов, алавитов или суфиев; суннитов-турок против алавитов-сирийцев; суннитов движения "Братья - мусульмане” против суннитов-ваххабитов или других “неверных". Эта глупость привела к катастрофе невероятного масштаба» [Эгдаль 2016: 318].

Как свидетельствуют данные, ЦРУ при Б.Х. Обаме покровительствовало «Братьям-мусульманам» даже в США. «Обама в Белом доме и Хиллари Клинтон в государственном департаменте продвигали членов организации и их сторонников на высшие посты в политической системе США. Ключевые члены этого движения занимали высокие политические должности в госдепартаменте, Белом доме и Министерстве внутренней безопасности. Последнее даже предоставляло лидерам “Братьев-мусульман” доступ в предназначенные для дипломатов VIP-зоны аэропортов» [Эгдаль 2016: 319].

Использование этой экстремистской религиозной организации должно было

${ }^{1}$ https://ria.ru/world/20151005/1297385538.html 
расширить программу по «демократизации» не только Ближнего Востока, но и Центральной Азии, Синцзяна. «Их целью [администрации США] было внесение хаоса на территорию Евразии, в треугольник Кавказ - Сирия - Синцзян (Китай), что позволило бы дестабилизировать крепнущие экономические и политические связи между Россией, Китаем, Ираном и странами Центральной Азии - странами формирующийся антигегемонистской коалиции, которой так опасался Бжезинский» [Эгдаль 2016: 323].

Но почему же для этой цели были нужны религиозные фигуры? Бесцеремонное попрание суверенитета стран (Ирака, Сирии) породило мощный антиамериканизм в арабском мире. Открытое вмешательство США оборачивалось против самих США. Ставка на религиозный фактор должна была скрыть истинную роль этого государства в дестабилизации и разрушении Ближнего Востока. «В любом случае правительству Соединенных Штатов необходимо было скрывать свою ключевую роль в организации таких мероприятий на Ближнем Востоке», - отмечает У. Энгдаль [Эгдаль 2016: 326].

«США использовали неправительственные организации, такие как Национальный Фонд поддержки демократии (NED), Freedom House, Фонды открытого общества (OSF) или неоконсервативный Комитет по современным угрозам (CPD), которые на самом деле получали государственное финансирование и действовали по хорошо отлаженной схеме, поддерживая оппозиционные группы и фракции, особенно религиозные, и тем самым обостряя внутренние противоречия в ставшей мишенью стране» [Эгдаль 2016: 326].

Появление терроризма стало одновременно не только средством достижения тех или иных политических целей, но и результатом вмешательства в жизнь традиционных исламских обществ, которое обострило и без того существующие в нем противоречия и конфликты, ведущие к ослаблению государств, подталкиванию к возможной смене правления (так называемым революциям различных видов). Совершенно очевидно, что Запад после окончания «холодной войны» видел в исламе («исламофашизме») препятствие для глобального доминирования. Однако желаемая «демократизация» не привела к исторической победе Запада, а создала угрозу всей западной цивилизации.

Таким образом, очевидно, что терроризм на Ближнем Востоке корреспондирует с другой технологией США, применяемой против независимых стран, - технологией «цветных революций», Арабской весны и имеет очевидный геополитический контекст. Без колоссальной финансовой, военной, организационной поддержки США и их союзников становление ДАИШ, как и глобальная угроза терроризма, не были бы возможными.

Не секрет, что геополитические цели США в значительной степени направлены и на снижение политического и экономического потенциала России на международной арене путем втягивания ее в «борьбу» с США, чтобы отвлечь внутренние экономические ресурсы на решение оборонных и специальных антитеррористических задач, формируя тем самым внутригосударственный конфликтный потенциал через определенное недовольство части населения такими действиями для его использования в политических целях. Особо можно отметить активно проводимую оппозиционными силами политику, направленную на свертывание борьбы с международным терроризмом за пределами государства, отказ от поддержки стран в этой борьбе, сокращение расходов на оборону и безопасность, призывы «войти в цивилизованный клуб европейских государств» на их условиях. Безусловно, это и есть цели «геополитического терроризма» США, к которым присоединяются и их западные союзники.

В современной политологии все более актуально звучит также вопрос о ведении так называемой прокси-войны. Террористов, если они представляют раз- 
ветвленную сеть, можно использовать в качестве субъекта, уполномоченного на ведение войны, тогда как заказчик остается в тени [Савин 2016: 172].

Выстраивание системы противостояния глобальному терроризму, очевидно, сегодня должно исходить из обоснованного предположения, что стратегический, геополитический компонент этого явления будет усиливаться. Будучи удобным и эффективным средством достижения глобальных целей, квазигосударственные структуры и сообщества типа ДАИШ будут не только появляться впредь, но и локализоваться в тех регионах, где сталкиваются геополитические интересы мировых держав.

Принимая меры по сохранению военной напряженности в регионах (прежде всего, с использованием националистических и экстремистских сил), максимально близких к территории России, используя методы террористической деятельности (в трактовке ст. 3 федерального закона «О противодействии терроризму»), США вынуждает Россию концентрировать дополнительные усилия на решении задач антитеррористической деятельности, противостоянии распространению «стратегического терроризма».

\section{Список литературы}

Алексеев О.Н. 2012. Причины, предпосылки, условия возникновения и распространения международного терроризма. - Право и общество. № 2(036). C. 134-141.

Бьюкенен П. 2006. Правые и неправые. М.: АСТ-Транзиткнига. 346 с.

Вейнер Т. 2013. ЦРУ. Правдивая история. М.: Центрполиграф. 728 с.

Савин Л. 2016. Новые способы ведения войны: как Америка строит империю. СПб: Питер. 352 с.

Стоун О., Кузник П. 2014. Нерассказанная история США. М.: КоЛибри; Азбука-Аттикус. 924 с.

Тьерри М. 2017. Преступления глубинного государства. М.: АСТ. 336 с.

Энгдаль У.Ф. 2016. Священные войны Западного мира. М.: Селадо. 336 с.

Thornton T.P. 1964. Terror as a Weapon of Political Agitation. - Internal War. Problems and Approaches (ed. by H. Eckstein). London: The Free Press of Glencoe Collier-Macmillan Limited. P. 71-99.

BLOKHIN Konstantin Vladimirovich, Cand.Sci. (Hist.), Leading Researcher of Security Studies Centre, Russian Academy of Sciences (21b Garibal'di St, Moscow, Russia, 117335; constantinos1@rambler.ru)

SINITSYN Igor' Mikhailovich, Scientific Secretary of Security Studies Centre, Russian Academy of Sciences (21b Garibal'di St, Moscow, Russia, 117335; IM_9380752@mail.ru)

\section{THE UNITED STATES' STRATEGIC TERRORISM AS A THREAT TO RUSSIA'S NATIONAL SECURITY: ITS GENESIS AND FEATURES}

\footnotetext{
Abstract. The proposed article is devoted to the study of the phenomenon of strategic terrorism as an element of the US global strategy for maintaining world domination and leadership, creating external threats to Russia's national security. The article deals with the genesis of this phenomenon, its nature, its connection with the proxy war.

Keywords: CIA, jihadism, US foreign policy, Russia's security, Al-Qaida, strategic terrorism, Middle East, geopolitics, religious factor of terrorism, proxy war
} 